\title{
Cure Kinetics of Cycloaliphatic Epoxy/Silica System for Electrical Insulation Materials in Outdoor Applications
}

\author{
Jae-Young Lee \\ Hydrogen Fuel Cell Parts and Applied Technology Regional Innovation Center, Woosuk University, Wanju 565-701, Korea
}

Jae-Jun Park ${ }^{\dagger}$, Jae-Seol Kim, Seong-Sik Shin, and Chan-Young Yoon

Department of Electrical and Electronic Engineering, Joongbu University, Geumsan 312-702, Korea

Jong-Hoon Cheong, Young-Woo Kim, and Geun-Bae Kang

Head \& Pyeongtaek Factory, Dongwoo Electric Co., Pyeongtaek 451-843, Korea

Received March 4, 2015; Revised March 13, 2015; Accepted March 17, 2015

The cure kinetics of a neat epoxy system and epoxy/silica composite were investigated by DSC analysis. A cycloaliphatic type epoxy resin was diglycidyl 1,2-cyclohexanedicarboxylate and curing agent was anhydride type. To estimate kinetic parameters, the Kissinger equation was used. The activation energy of the neat epoxy system was $88.9 \mathrm{~kJ} / \mathrm{mol}$ and pre-exponential factor was $2.64 \times 10^{12} \mathrm{~min}^{-1}$, while the activation energy and pre-exponential factor for epoxy/silica composite were $97.4 \mathrm{~kJ} / \mathrm{mol}$ and $9.21 \times 10^{12} \mathrm{~min}^{-1}$, respectively. These values showed that the silica particles have effects on the cure kinetics of the neat epoxy matrix.

Keywords: Cure kinetics, Kissinger equation, Cycloaliphatic epoxy, Epoxy/silica composite, Epoxysilane-treated silica, Electrical insulators

\section{INTRODUCTION}

Epoxy resins were the first polymers used for electrical equipments, such as mold-type transformers, current transformers (CT), potential transformers (PT), metering out-fit (MOF), and gas switching gears in the fields of solid electrical insulators since the mid-1940s, and are still used to make electrical insulators for indoor and outdoor applications [1-3]. This was because they have good mechanical and thermal properties as well as excellent electrical properties [4,5]. Especially for outdoor insulation, cycloaliphatic epoxy families have been used for high voltage (HV) applications since the 1960s because aliphatic

${ }^{\dagger}$ Author to whom all correspondence should be addressed: E-mail: jjpark@joongbu.ac.kr

Copyright (C2015 KIEEME. All rights reserved. cyclic structure are superior to aromatic bisphenol structure in the resistance to UV radiation, carbon formation, and surface discharges [3].

In many electrical applications, insulation materials play a key role in the equipment's functionality. Thus, it is very important to know the materials' characteristics, which would help us in planning the investigations of power systems and developing new material systems. Whether in an epoxy system, it must be fully cured to maximize insulation properties, the cure degree of the epoxy is determined by the cure conditions: thecure temperature. Thus, the cure reaction rate must be studied to determine the optimal cure conditions. There are many methods to study cure kinetics and the best known is the issinger method [6,7] as follows:

$$
-\ln \frac{q}{T_{p}^{2}}=\frac{E_{a}}{R} \times \frac{1}{T_{p}}-\ln \frac{A R}{E_{a}}
$$


where q: heating rate, $\mathrm{T}_{\mathrm{p}}$ : the temperature where the maximum conversion rate occurs, based on a DSC curve, $\mathrm{E}_{\mathrm{a}}$ : activation energy for curing reaction, A: pre-exponential factor and R: gas constant, $8.314 \mathrm{~J} / \mathrm{mol} / \mathrm{K}$. From the relationship between $-\ln (\mathrm{q} /$ $\left.\mathrm{T}_{\mathrm{p}}\right)$ and $\left(1 / \mathrm{T}_{\mathrm{p}}\right)$, activation energy and pre-exponential factor can be calculated from the slope and y-intersect, respectively.

In this study, an epoxy/silica composite was prepared by mixing a micro-sized silica-treated epoxy-type silane coupling agent with a cycloaliphatic epoxy resin to apply the microcomposite to an outdoor electrical insulator, and cure kinetics was studied by introducing the differential scanning calorimetry (DSC) data to the Kissinger equation.

\section{EXPERIMENTS}

\subsection{Materials}

An cycloaliphatic epoxy resin, diglycidyl 1,2-cyclohexanedicarboxylate (CY 184, Huntsman Co.) was used. The equivalent weight was 164-72 g/eq and the viscosity was $700 \sim 900 \mathrm{mPa} \cdot \mathrm{s}$ at $25^{\circ} \mathrm{C}$. An cycloaliphatic anhydride hardener, 1,2-cyclohexanedicarboxylic anhydride (HY 1235, Huntsman Co.) was used. Its anhydride content was $\geq 98 \%$ and the viscosity was $70 \sim 80 \mathrm{mPa} \cdot \mathrm{s}$ at $25^{\circ} \mathrm{C}$. A tertiary amine, benzyldimethyl amine (DY 062, Huntsman Co.) was used as an accelerator. Their chemical structures are as follows.<smiles>CC(C)(C)[Mg]</smiles><smiles>O=C1OC(=O)C2CCCCC12</smiles>

(HY 1235)<smiles>CN(C)Cc1ccccc1</smiles>

(DY 062)
Epoxysilane-treated silica was used as an inorganic filler (purchased from Quarzwerke $\mathrm{GmbH}$ ). The particle size ranged from $2.68 \mu \mathrm{m}$ to $724.43 \mu \mathrm{m}$ and the average particle size was $37.56 \mu \mathrm{m}$ (Fig. 1). Particle size was analyzed with a Mastersizer 2000 (Malvern Instruments).

Figure 2 shows the morphology of the micro-sized silica. The filler had various irregular particle shapes and sizes. Its morphology was very rough and sharp. Field emission scanning electron microscopy (FE-SEM, JMS-6701F, JEOL) was performed at an acceleration voltage of $10 \mathrm{kV}$.

\subsection{DSC Analysis}

Sample preparation procedure for DSC analysis was as fol-

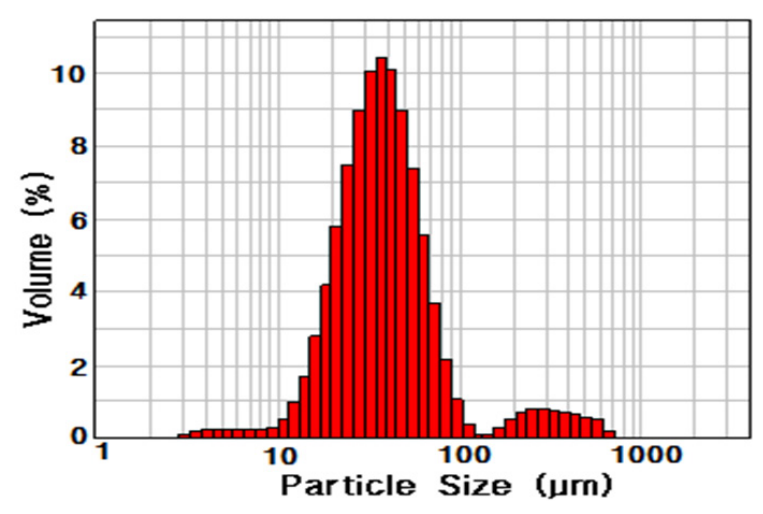

Fig. 1. Particle size distribution of epoxysilane treated silica.

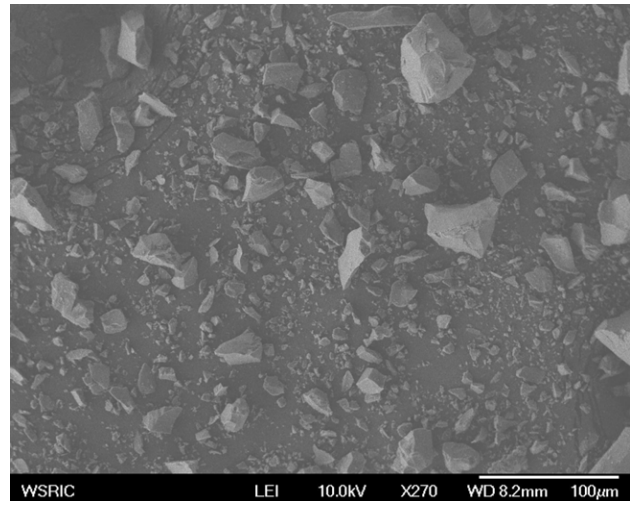

Fig. 2. SEM of epoxysilane-treated silica.

lows. To prepare the neat epoxy system, epoxy base resin (100 g), curing agent (90 phr) and accelerator $(0.6 \mathrm{phr})$ were mixed well using a mechanical stirrer. To prepare the epoxy/silica microcomposite, epoxysilane-reated silica (290 phr) was mixed homogeneously with epoxy base resin (100 g) for $1 \mathrm{~h}$ using a mechanical stirrer and the mixture was mixed with curing agent (90 phr) and accelerator ( $0.6 \mathrm{phr}$ ) using a mechanical stirrer. The unit 'phr' indicates parts per $100 \mathrm{~g}$ of epoxy base resin.

Dynamic DSC analysis was performed as follows. The mixed sample was weighed exactly (about 3 4 mg) in an aluminum pan and it was loaded into the DSC furnace (Instrument Specialists Incorporated, DSC Infinity Series, USA) and then DSC analysis was performed at heating rates of $2,5,10$, and $20^{\circ} \mathrm{C} / \mathrm{min}$. Nitrogen flowed at $40 \mathrm{~mL} / \mathrm{min}$ to purge the furnace and to prevent oxidation of the samples.

\section{RESULTS AND DISCUSSION}

Figure 3 shows DSC curve for the neat epoxy system at $10^{\circ} \mathrm{C}$ $/ \mathrm{min}$. The cure reaction took place in one stage and the total exothermic heat was $124.5 \pm 2.5 \mathrm{~kJ} / \mathrm{mol}$ (epoxide group). The base line was taken as the tangent to the DSC curve at each point. The exothermic curve started from about $97^{\circ} \mathrm{C}$, and the temperature of the maximum peak value was at $149.2^{\circ} \mathrm{C}$. The exothermic heat was due to the reaction between the epoxide group and the carboxyl group.

Figure 4 shows DSC curves for neat epoxy system at four different heating rates. The cure reaction took place in one stage regardless of heating rate and the temperature of the maximum peak value increased with increasing heating rate, as shown in Table 1. This was because the cure reaction of epoxy resin took place rapidly in a short time as cure rate increased. To use the Kissinger equation, the relationship between $-\ln \left(\mathrm{q} / \mathrm{T}_{\mathrm{p}}\right)$ and $(1 /$ $\mathrm{T}_{\mathrm{p}}$ ) was also listed on Table 1 and displayed in Fig. 5. The straight line was expressed as

$$
-\ln \frac{q}{T_{P}^{2}}=10.69 \times 10^{3} \frac{1}{T_{p}}-15.23
$$

The slope was corresponded to Ea/R and the $\mathrm{y}$-intersect was to $\ln \left(\mathrm{AR} / \mathrm{E}_{\mathrm{a}}\right)$, so the activation energy of cure reaction was 88.9 $\mathrm{kJ} / \mathrm{mol}$ and pre-exponential factor was $2.64 \times 10^{12} \mathrm{~min}^{-1}$. The Kissinger equation is a useful and accurate expression for $\mathrm{n}^{\text {th }}$ order reactions, but this equation is not expressed by the reaction order term, n. Kissinger proposed this equation for first-order 


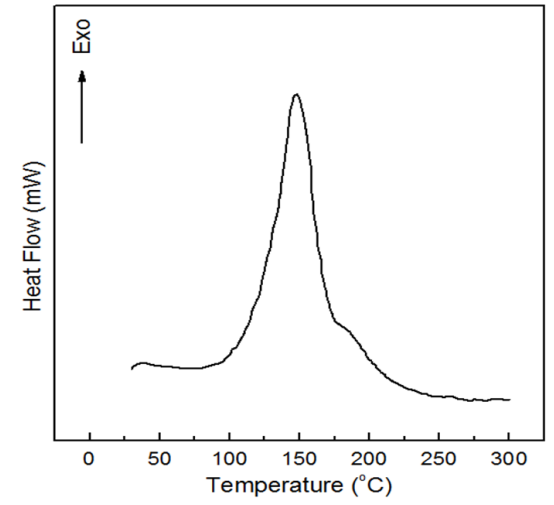

Fig. 3. DSC curve for neat epoxy system.

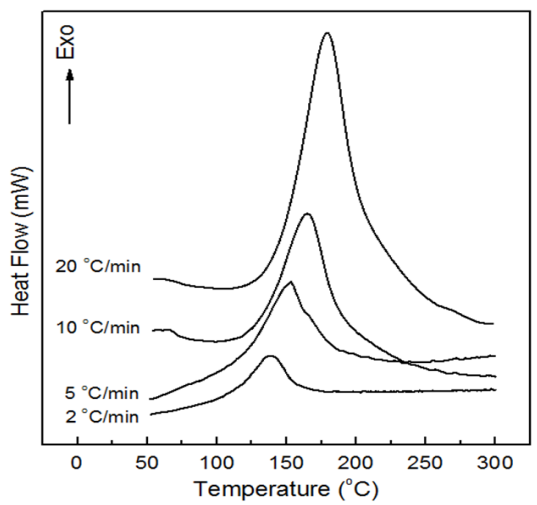

Fig. 4. DSC curves for neat epoxy system at various heating rates.

Table 1. Cure kinetic parameters for neat epoxy system.

\begin{tabular}{cccc}
\hline $\mathrm{q}(\mathrm{K} / \mathrm{min})$ & $\mathrm{T}_{\mathrm{p}}(\mathrm{K})$ & $-\ln \left(\mathrm{q} / \mathrm{T}_{\mathrm{p}}{ }^{2}\right)$ & $1 / \mathrm{T}_{\mathrm{p}} \times 10^{3}\left(\mathrm{~K}^{-1}\right)$ \\
\hline 2 & 401.00 & 11.29 & 2.49 \\
5 & 409.20 & 10.42 & 2.44 \\
10 & 421.04 & 9.78 & 2.37 \\
20 & 434.79 & 9.15 & 2.30 \\
\hline
\end{tabular}

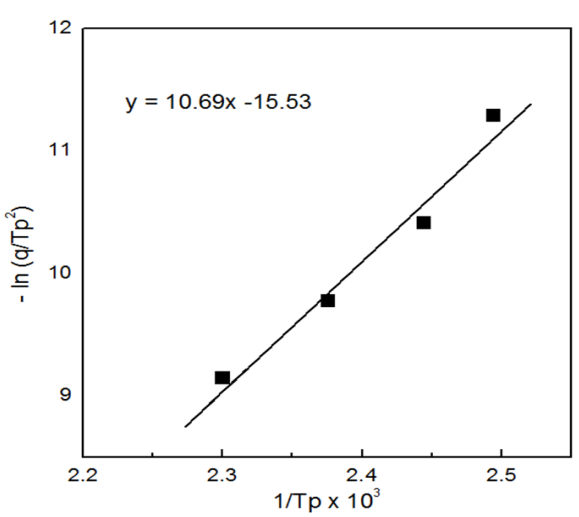

Fig. 5. Kissinger plot for neat epoxy system.

reactions, and Prime showed this equation to be applicable to $\mathrm{n}^{\text {th }}$ order reactions of epoxy resin [8].

Figure 6 shows the curves obtained by dynamic DSC scans for epoxy/silica microcomposite at different heating rates. The cure reaction of the composite system also took place in one stage

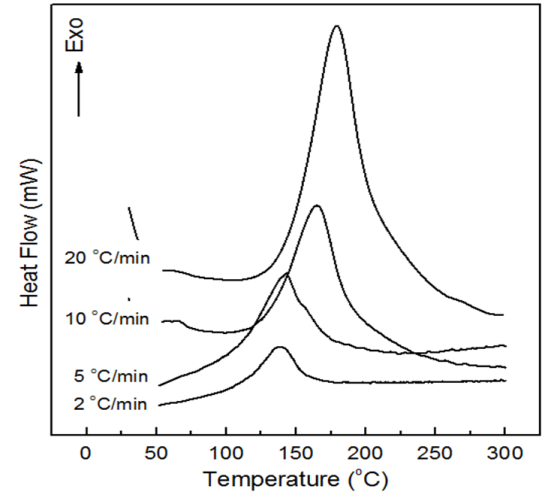

Fig. 6. DSC curves for epoxy/silica microcomposite at various heating rates.

Table 2. Cure kinetic parameters for epoxy/silica microcomposite.

\begin{tabular}{cccc}
\hline $\mathrm{q}(\mathrm{K} / \mathrm{min})$ & $\mathrm{T}_{\mathrm{p}}(\mathrm{K})$ & $-\ln \left(\mathrm{q} / \mathrm{T}_{\mathrm{p}}{ }^{2}\right)$ & $1 / \mathrm{T}_{\mathrm{p}} \times 10^{3}\left(\mathrm{~K}^{-1}\right)$ \\
\hline \hline 2 & 410.89 & 11.34 & 2.43 \\
5 & 425.15 & 10.49 & 2.35 \\
10 & 438.32 & 9.86 & 2.28 \\
20 & 452.16 & 9.23 & 2.21 \\
\hline
\end{tabular}

regardless of heating rate and the temperature of the maximum peak value increased with increasing heating rate as shown in Table 2. The Tp value for the composite system was higher, by about $10 \sim 18^{\circ} \mathrm{C}$, than those in the neat system without epoxysilane-treated silica. The Kissinger parameters for epoxy/silica microcomposite were also listed on Table 2 and the relationship between $-\ln \left(\frac{q}{T_{p}}\right)$ and $\left(\frac{1}{T_{p}}\right)$ is also listed in Table 1 and displayed in Fig. 5. The straight line was expressed as

$$
-\ln \frac{q}{T_{P}^{2}}=11.72 \times 10^{3} \frac{1}{T_{p}}-9.48
$$

The activation energy and pre-exponential factor could be calculated; they were $97.4 \mathrm{~kJ} / \mathrm{mol}$ and $9.21 \times 10^{12} \mathrm{~min}-1$, respectively. In the Arrhenius model [9], the activation energy may be defined as the minimum energy required to start a chemical reaction, and pre-exponential factor is the collision frequency of reactions. That is, increasing collisions with lower activation energy increase the rate of reaction. Thus, the results of increasing peak temperature and high activation energy imply that the cure reaction in epoxy/silica microcomposite takes place with more difficultly and needs more energy than that of the neat epoxy system. In addition, the pre-exponential factor for epoxy/silica microcomposite is 3.5 times lower than that of the neat epoxy system. This means that the collision between epoxide group and carboxyl group was interrupted by a silica particle. These values indicate that the silica particles have an effect on the cure kinetics of the neat epoxy matrix.

\section{CONCLUSIONS}

An poxy/silica composite for an electrical insulator for outdoor applications was prepared by mixing a cycloaliphatic epoxy resin (diglycidyl 1,2-cyclohexanedicarboxylate), a curing agent (1,2-cy- 


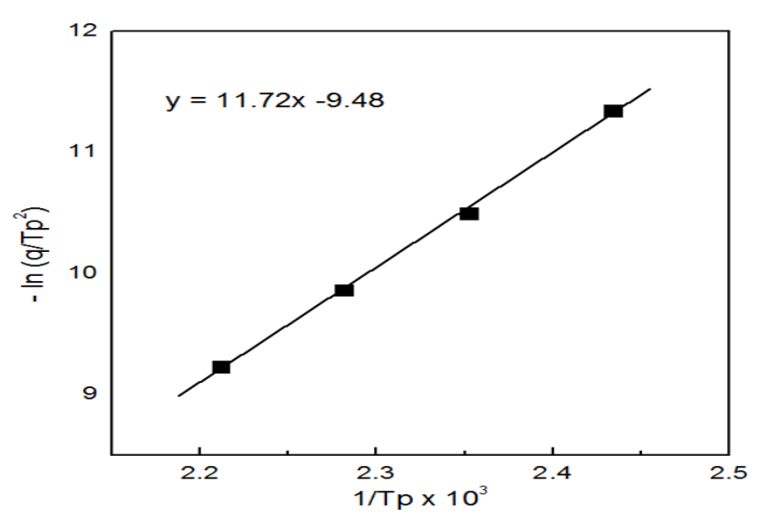

Fig. 7. Kissinger plot for epoxy/silica microcomposite.

clohexanedicarboxylic anhydride), and epoxysilane-treated microsilica and the cure kinetics were investigated by DSC analysis. To estimate kinetic parameters, the Kissinger equation was used The activation energy of the neat epoxy system was $88.9 \mathrm{~kJ} / \mathrm{mol}$ and pre-exponential factor was $2.64 \times 10^{12} \mathrm{~min}^{-1}$, while the activation energy and pre-exponential factor for the epoxy/silica composite were $97.4 \mathrm{~kJ} / \mathrm{mol}$ and $9.21 \times 10^{12} \mathrm{~min}^{-1}$, respectively. These values indicate that the silica particles affect the cure kinetics of the neat epoxy matrix. It means that the collisions between epoxide groups and carboxyl groups are interrupted by silica particle.

\section{ACKNOWLEDGMENTS}

This work was financially supported by a grant (S2175492) from the Convergence Technology Program of the Small \& Medium Business Administration (SMBA), Korea in 2014. It was also supported by Joongbu University in 2014.

\section{REFERENCES}

[1] D. A. Bolon, IEEE Electr. Insul. Magazine, 11, 10 (1995). [DOI: http://dx.doi.org/10.1109/57.400759].

[2] R. S. Gorur, E. A. Cherney, and J. T. Burnham, Outdoor Insulators, ISBN 10:0967761107 (1999).

[3] G. Iyer, R. S. Gorur, A. Krivda, and P. Mahonen, Proceedings of the 16th International Symposium on High Voltage Engineering, Paper E-2 (2009).

[4] Y. S. Cho, M. J. Shim, and S. W. Kim, Mater. Chem. Phys., 66, 70 (2000). [DOI: http://dx.doi.org/10.1016/S0254-0584(00)002728].

[5] R. Sarathi, R. K. Sahu, and P. Rajeshkumar, Mater. Sci. Eng.: A, 445, 567 (2007). [DOI: http://dx.doi.org/10.1016/ j.msea.2006.09.077].

[6] R. B. Prime, Thermal Characterization of Polymeric Materials, E. A. Turi (ed.) (Academic Press, New York, 1982).

[7] J. J. Park, Trans. Electr. Electron. Mater., 13, 204 (2012). [DOI : http://dx.doi.org/10.4313/TEEM.2012.13.4.204].

[8] P. B. Prime, Thermal Characterization of Polymeric Materials, E. A. Turi (ed.) (Academic Press, New York, 1982). 